\title{
Emotional and psychological impact of abortion: a critique of the literature
}

\section{Edna Astbury-Ward}

\section{Background}

Defining women's emotional experiences associated with abortion is a difficult task. Many circumstantial factors affect women's emotional journeys during their abortion experience and beyond. The research into this aspect of abortion is riven with methodological flaws and bias. ${ }^{1}$ Steering a neutral path through the vast amount of literature on this subject is a complex process. Much variation exists within the literature on the subject of women's emotional and psychological experiences of abortion but many clinical studies document the safety and efficacy of physical abortion procedures. ${ }^{2-6}$ However, very few large-scale studies examine the patients' psychological experience of abortion. ${ }^{7}$ Gathering evidence of women's experiences of abortion is a difficult terrain to negotiate partly because the stigma associated with abortion militates against women's disclosure. ${ }^{8}$ Accordingly, women who have elected to undergo abortion may not welcome contact about their experience and they may be reluctant to participate in research studies about abortion. ${ }^{9}$ The following critique examines the evidence from a variety of sources on the subject of women's emotional experiences associated with abortion. It concentrates mainly on abortion care in the UK but includes, where relevant, evidence from other countries (chiefly the USA and Europe). Source material comprises empirical studies, guidelines, protocols, and commentary and analysis from peer-reviewed journals.

\section{Introduction to the literature}

When reading literature that examines women's emotions during their abortion journey, caution and a critical eye should be cast on indicators such as author affiliation, purpose of the research and the robustness and reliability of the study. This is important when critically reading any literature, but especially so when the subject matter arouses strong personal opinion from both the author and the reader. Judicious scrutiny is particularly relevant when reading studies reported from countries where the topic of abortion is also the subject of political pontificating.

Researcher/author preference or experience may influence which approach is taken to a study and consequently may be reflected in the outcomes of the final paper. The study design and the manner in which data are collected and analysed are all important to the critical reading of literature on this topic. Roberts et al. (2006) suggest that it is helpful if the research process is transparent so that the reader can understand decision processes,

J Fam Plann Reprod Health Care 2008; 34(3): 181-184

(Accepted 7 May 2008)

North East Wales Institute of Higher Education, Centre for Health and Community Research, Wrexham and Western Cheshire Primary Care Trust, Countess of Chester Hospital, Chester, UK

Edna Astbury-Ward, MSc Sexual Medicine, RGN, Doctoral Research Fellow and Contraception and Sexual Health Specialist Nurse

Correspondence to: Mrs Edna Astbury-Ward, North East Wales Institute of Higher Education, Centre for Health and Community Research, Plas Coch Campus, Mold Road, Wrexham LL11 2AW, UK. E-mail: e.astburyward@newi.ac.uk researcher orientation to the study and the context in which the study was undertaken. ${ }^{10}$ As mentioned previously, there is a lack of large-scale studies on this subject and this is most likely for two reasons: (1) because the subject matter (women's emotional and psychological experiences of abortion) are not easily quantifiable so consequently do not lend themselves to numerical representation and (2) women are reluctant to take part in research associated with abortion. As such, the subject may be better explored using a qualitative methodology. A brief discussion of qualitative research follows, however it is beyond the scope of this review to discuss in detail the merits and disadvantages of quantitative versus qualitative methods.

Specific benefits of using a qualitative methodology Qualitative methods are becoming increasingly popular in health care research because they have the potential to inform practice and can enrich our understanding of complex human behaviours and attitudes. ${ }^{11}$ Arguably one of the strengths of a qualitative approach is the ability to generate a vivid and valid account of the participants' experiences. The literature also suggests that qualitative research design allows the researcher to understand the intricate details about feelings, thought processes and emotions that are often difficult to explore using more conventional research methods. ${ }^{12}$

\section{Limitations of qualitative research methods}

Qualitative research reports are often read to gain knowledge and insights that help to understand, explain and ultimately shape experiences that the reader may encounter in their practice. Reports of qualitative research often use the voices of participants to tell the story of the phenomenon under study. Such narratives frequently resonate with clinicians' experiences and are thus often perceived as very readable and applicable. The highly subjective nature of the approach may make findings idiosyncratic and difficult to replicate or apply to settings outside of the research environment. ${ }^{13}$

\section{Review of the literature}

Whilst critiquing the literature for this review, the range of variance in research results which seemingly investigated similar occurrences was noticed, for example, the much debated subject of the existence of 'post traumatic abortion syndrome' and the rate and type of psychological sequelae of abortion being examples of just two. The following paragraphs will highlight examples of the variance in the findings of the literature.

The literature agrees that emotions play a central role in most important life events. Bailey, quoting Professor Ray Dolan of University College, London, writes in an interview "that emotions influence our decisions all the time" (p. 29). ${ }^{14}$ It is also agreed that the psychological element of abortion cannot be ignored because abortion is, without doubt, an important life event causing high psychological stress at the time. ${ }^{15}$ Argent suggests that abortion may involve feelings of guilt, shame and regret. ${ }^{16}$ Yet others disagree, suggesting that the experience of abortion is emotionally benign despite acknowledgement in the same article that "abortion represents one of the most contentious political, social and moral issues of the day". 17 
The literature on this subject draws on a variety of empirical research in an attempt to describe the range of emotions women feel during their journey through abortion and beyond. The literature has included post-abortion studies conducted as early as a few hours post-abortion ${ }^{18}$ to studies conducted as long as 27 years post-abortion, ${ }^{19}$ and yet still there seems no consensus on what women do, or do not, experience. Avalos (1999) suggests from her qualitative in-depth interviews with 20 women that this is because women's retrospective understandings of abortion are not static and that meanings are different for each woman at varying stages in their lives. Avalos considers that the passage of time is an important variable when women consider their abortion in later years. She further argues that static models have guided research in this field even though women's lives continually grow and change. 19

Despite the vast amount written, the literature does not do justice to the complexity and depth of individuals' abortion experiences and current research on this important topic is inadequate and inconclusive. ${ }^{20,21}$ Additionally, the question of what type of emotions women experience is not answered despite documented research efforts over the past 30 years. Indeed, in a position statement by the Royal College of Psychiatrists on 14 March 2008, the College concludes that the specific issue of whether or not abortion has harmful effects on women's mental health "remains to be fully resolved". ${ }^{21}$ However, there are other reasons for the lack of clarity in establishing what emotional experiences women may experience, namely that it is difficult to isolate the emotional effects of abortion without considering confounding variables such as the social or psychiatric factors of the individual and the context in which they experienced the abortion. ${ }^{22}$

The literature surrounding this subject contains many biases. Some arise from the ideological viewpoints or assumptions of the authors ${ }^{23}$ and some arise because of poor methodology. ${ }^{1}$ Some literature is biased toward the expectation of severe negative reactions of women who have experienced abortion and some authors are highly critical of this. These authors highlight the inappropriate generalisation of conclusions from these studies and suggest they are "of limited scientific merit and tell little about the experience of the vast majority of abortion patients" (p. 1197). ${ }^{23}$

There is much less documented information regarding the potential positive effects that abortion may bring to the women, or the effects on women when abortion is denied, an exception being the paper by Dagg (1991). ${ }^{24}$ The literature tends to suggest that women who do not experience distress following abortion may experience more positive emotions such as relief, satisfaction and a sense of return to normality. ${ }^{25}$

Post-abortion emotions vary greatly between women, and therefore it would be misrepresentative to present abortion as a process that is inevitably associated with suffering and grief. Indeed to do so might encourage women who do not act in this way to consider themselves 'deviant' (p. 111). ${ }^{26}$ For this reason it is recommended that interpretation of research on post-abortion experiences must consider the entire context of the abortion and the circumstances in which the research took place. In some instances scrutiny of the origin and quality of references related to long-term psychological sequelae is advisable because of bias contained within them.

\section{Rates of post-abortion psychological sequelae}

One aspect of post-abortion experience that researchers and the literature do appear to agree on concerns the number of women who experience long-term psychological sequelae comprising mainly depressive and anxiety symptoms. ${ }^{27}$ There is a consensus that approximately $10 \%$ of women experience long-term psychological sequelae. ${ }^{19-22}$ Interestingly, for the $10 \%$ of women who do experience long-term psychological sequelae there is an acknowledgement that a minority of these women may require inpatient psychiatric hospital admission. ${ }^{28}$ The contrasting findings within the literature on long-term psychological sequelae only serve to highlight the difficulties that doctors and other health care professionals face when assessing whether abortion is causal, associated with, or even incidental to, subsequent depression.

\section{Risk factors for long-term adverse psychological sequelae post-abortion}

The $10 \%$ of women who experience long-term psychological sequelae are more likely to display certain characteristics and demographic similarities that are more likely to predispose them to severe psychological effects. These include previous psychiatric history, poor relationships with others (especially mother or partner), older multiparous women with existing children, and religious affiliation. In addition it has been found that women who are younger, and those with low self-esteem and poor social support, are at greater risk of long-term adverse psychological outcomes ${ }^{17}$ Women who have experienced multiple abortions, and those who experienced ambivalence in deciding on abortion, have been shown to be more likely to suffer long-term adverse psychological outcomes. ${ }^{15}$ Ambivalence is a significant confounding feature associated with the decision-making process. Accordingly, ambivalence or conflict surrounding the abortion decision is one of the most potent predictors of problematic post-abortion emotional adjustment. Some authors suggest that all women confronted with an unwanted pregnancy may experience some level of ambivalence. 17

\section{Making the decision}

The decision to have an abortion is not an easy one. The final decision is likely to represent a culmination of mixed emotions and external circumstances that are not well understood. A fuller appraisal of the life circumstances within which women decide to have an abortion is warranted because the decision is typically motivated by diverse interrelated reasons. ${ }^{26-29}$

Returning to Argent's suggestion that abortion is associated with guilt, ${ }^{16}$ findings in the literature suggest this is more likely in instances where the woman has initially bonded with, and made a commitment to, the pregnancy. ${ }^{17}$ Defining a concept of bonding and the prenatal attachment that women develop towards their fetus is clearly a difficult task, and it is infrequently and poorly addressed in the literature. The concept of prenatal attachment offers a partial explanation as to why women may experience the emotion of loss when they reject their fetus and opt for abortion. Mueller and Mercer's definition (1993) of prenatal attachment as "a unique affectionate relationship that develops between a woman and her fetus" (p. 201 $)^{30}$ indicates why some women may experience internal conflict when choosing abortion. According to the Marie Stopes organisation, initially making a commitment to the pregnancy and then having a change of mind may be a function of altered personal circumstances and this may result in delaying the request for abortion. ${ }^{31}$ Delay in requesting abortion because of ambivalence or denial of the pregnancy is mainly associated with women in the younger 
age group. ${ }^{32}$ Unfortunately, this delay necessitates the use of abortion procedures that are associated with heightened physical and emotional risk.

The literature suggests that the emotion of loss is greater amongst women who abort a 'meaningful' pregnancy (i.e. a pregnancy that was initially wanted) and this is associated with post-abortion psychological implications. ${ }^{33}$ According to Avalos, the passage of time allows women to address issues they were not able to process or articulate at the time of the abortion. Avalos' empirical study of in-depth interviews with 20 women who had experienced abortion postulates that this might be because personal growth and changing circumstances prompt women to re-evaluate the original experience, and that retrospective interpretations of the abortion experience are subject to change over time. ${ }^{19}$ Additionally, women experience intervening life events that lead them to reappraise a previous abortion in either a more positive or negative light. Women's evaluations and individual experiences of the abortion procedure may also affect how they experience subsequent emotions. Levels of grief after abortion may depend on the 'wantedness' or 'intendedness' of the pregnancy and this may have implications for the provision of post-abortion counselling or follow-up.

\section{Society and abortion: findings in the literature}

Hodson (2002) makes the interesting point that some women are denied social support for their loss when they choose abortion that might not have been denied had they miscarried. ${ }^{34}$ Zoja (1998) argues that denying social support for induced elective abortion prevails because of society's belief that finds pregnancy an acceptable joy. 35 Some of the literature claims that society's attitudes towards pregnancy and birth are morally committed to protect babies. ${ }^{36}$ For example, Rando (1986), in her book Parental Loss of a Child, argues that abortion is a socially negated loss. ${ }^{37}$ Social negation is described by Rando as a situation in which the loss is not socially defined as loss. Hence, unresolved grief following abortion may not (according to Rando) be socially perceived as appropriate. Similarly, Barger-Williams (1991) suggests that in order for women to engage in the process of grieving following abortion, the loss must be acknowledged by self and others. ${ }^{38}$ Moreover, in common with Hodson, ${ }^{34}$ BargerWilliams continues that women are reluctant to express their emotions since their loss is considered socially unacceptable. All 82 participants in Barger-William's study experienced grief in some form, and she concludes that lack of acknowledgement of loss may have been a contributing factor. These findings support Dyson and While (1999) who claim that loss of a pregnancy in any circumstances is bereavement. ${ }^{39}$ These authors further state that when pregnancy loss is concealed and cannot be acknowledged, publicly mourned or socially supported, woman may experience isolation, shame and guilt, which supports Argent's argument. ${ }^{16}$

\section{Concealment of abortion}

Trybulski's study of women's long-term post-abortion experiences found that most of the 17 interviewees concealed their abortion because of shame or fear of adverse reactions from family and friends. ${ }^{33}$ Increased secrecy, the study claims, leads to the development of thought suppression, an increase in intrusive thoughts, and that decreased emotional openness may be a factor in postabortion resolution. Similarly, a cross-sectional study of 797 women who underwent surgical abortion in the USA found that the desire for anonymity when using abortion services led many eligible women to decline claiming against their medical insurers for their treatment. This phenomenon is referred to in the study as "the silent consumer". 40

\section{Conclusions}

It is evident from reviewing the literature that emotional responses following abortion are multiple and profound, and that abortion carries many complex and often paradoxical responses. Emotions throughout the abortion journey are ever changing. The way women experience abortion depends on complex processes that integrate multidimensional determinants of emotional, physical, cultural, psychosocial and psychological aspects. Attempting to define women's abortion experience is like attempting to understand what a patient means when asked to describe pain; they may use a variety of words that we recognise but we can never fully understand, and at best we can only interpret the event they experience.

The current literature does not do justice to the complexity and range of emotions that women experience after abortion. This is due in part to methodological flaws and bias. Because women's emotions are not static, the use of a more flexible model that measures women's emotions on a continuum may help to map the depth and range of these emotions, and this may be achieved by further exploring the issues with qualitative longitudinal studies. More research into this vast and complex area is needed. Understanding what emotional responses women experience after abortion may also help to identify why abortion is not always a singularly unique event in a woman's life, and may offer some insight into the psychological reasons accounting for repeat abortion.

Statements on funding and competing interests

Funding None identified.

Competing interests None identified.

\section{References}

1 Stotland N. Psychiatric aspects of induced abortion. Arch Womens Mental Health 2001; 4: 27-31

2 Grimes D, Schulz K, Cates W. Prevention of uterine perforation during curettage abortion. JAMA 1984; 251: 2108-2111.

3 Buehler J, Schulz K, Grimes D, Hogue C. The risk of serious complications from induced abortion: do personal characteristics make a difference? Am J Obstet Gynecol 1985; 153: $14-19$.

4 Royal College of General Practitioners, Royal College of Obstetricians and Gynaecologists. Induced abortion operations and their early sequelae. Joint study of the Royal College of General Practitioners and the Royal College of Obstetricians and Gynaecologists. J R Coll Gen Pract 1985; 35: 175-180.

5 Jacot F, Poulin C, Bilodeau A, Morin M, Moreau S, Gendron F, et al. A five-year experience with second-trimester induced abortions: no increase in complication rate as compared to the first trimester. Am J Obstet Gynecol 1993; 168: 633-637.

6 Royal College of Obstetricians and Gynaecologists (RCOG). Advanced Training Skills Module in Abortion Care. London, UK: RCOG Press, 2007.

7 Slade P, Heke S, Fletcher J, Stewart P. Termination of pregnancy: patients' perception of care. J Fam Plann Reprod Health Care 2001; 27: 72-77.

8 Boorer C, Murty J. Experiences of termination of pregnancy in a stand-alone clinic situation. J Fam Plann Reprod Health Care 2001; 27: 97-98.

9 Howie F, Henshaw R, Naji S, Russell I, Templeton A. Medical abortion or surgical aspiration? Two year follow up of a patient preference trial. Br J Obstet Gynaecol 1997; 104: 829-833.

10 Roberts P, Priest H, Traynor M. Reliability and validity in research. Nurs Stand 2006; 20: 41-45.

11 Clarke A. The benefits of using qualitative research. Prof Nurse 1998; 13: 845-847.

12 Broussard L. Understanding qualitative research: a school nurse perspective. J School Nurs 2006; 22: 212-218.

13 Polit D, Beck C, Hungler B. Essentials of Nursing Research: Methods, Appraisal, and Utilization (5th edn). New York, NY: Lippincott, Williams, and Wilkins, 2001. 
14 Bailey P. Emotional decisions. Wellcome Science 2007; 6: 29-32.

15 Hemmerling A, Siedentopf $F$, Kentenich $\mathrm{H}$. Emotional impact and accessibility of medical abortion with mifepristone: a German experience. J Psychosom Obstet Gynaecol 2005; 26: 23-31.

16 Argent V. Induced abortion. The Obstetrician and Gynaecologist 2000; 2: 2.

17 Coleman P, Reardon D, Strahan T, Cougle J. The psychology of abortion: a review and suggestions for future research. Psychol Health 2005; 20: 237-271.

18 Major B, Cozzarelli C, Cooper L, Zubeck J, Richards C, Wilhite $\mathrm{M}$, et al. Psychological responses of women after first-trimester abortion. Arch Gen Psychiatry 2000; 57: 777-784.

19 Avalos L. Hindsight and the abortion experience: what abortion means to women years later. Gender Issues 1999; 17: 35-57.

20 Coleman P, Nelson E. The quality of abortion decisions and college students' reports of post-abortion emotional sequelae and abortion attitudes. J Soc Clin Psychol 1998; 17: 425-443.

21 Royal College of Psychiatrists. Position Statement on Women's Mental Health in Relation to Induced Abortion, 14 March 2008. http://www.rcpsych.ac.uk/members/currentissues/mentalhealth andabortion.aspx [Accessed 2 May 2008].

22 Gilchrist A, Hannaford P, Frank P, Kay C. Termination of pregnancy and psychiatric morbidity. Br J Psychiatry 1995; 167: 243-248.

23 Adler N, David H, Major B, Roth S, Russo N, Wyatt G. Psychological factors in abortion: a review. Am Psychol 1992; 47: 1194-1204.

24 Dagg P. The psychological sequelae of therapeutic abortion denied and completed. Am J Psychiatry 1991; 148: 578-584.

25 Goodwin P, Ogden J. Women's reflections upon their past abortions: an exploration of how and why emotional reactions change over time. Psychol Health 2007; 22: 231-248.

26 Boyle M. Re-thinking Abortion: Psychology, Gender, Power and the Law. London, UK: Routledge, 1997.

27 Bradshaw Z, Slade P. The effects of induced abortion on emotional experiences and relationships: a critical review of the literature. Clin Psychol Rev 2003; 23: 929-958.
28 Zolese G, Blacker C. The psychological complications of therapeutic abortion. Br J Psychiatry 1998; 160: 742-749.

29 Söderberg H, Janzon L, Sjöberg N-O. Emotional distress following induced abortion. A study of its incidence and determinants among abortees in Malmö, Sweden. Eur J Obstet Gynecol Reprod Biol 1998; 79: 173-178.

30 Muller M, Mercer R. Development of the prenatal attachment inventory. West J Nurs Res 1993; 15: 199-215.

31 Marie Stopes International. Late Abortion: A Research Study of Women Undergoing Abortion Between 19 and 24 Weeks Gestation. 2005. http://www.mariestopes.org.uk/documents/ Late\%20abortion.pdf [Accessed 2 May 2008].

32 Ingham R, Lee E, Clements S, Stone N. Second Trimester Abortions in England and Wales. 2007. Centre for Sexual Health Research, School of Psychology, University of Southampton and School of Social Policy, Sociology and Social Research University of Kent, Canterbury, UK.

33 Trybulski J. The long-term phenomena of women's postabortion experiences. West $J$ Nurs Res 2005; 27: 559-576.

34 Hodson P. A woman's right to choose counselling. J Fam Plann Reprod Health Care 2002; 28: 174-175.

35 Zoja E. Abortion: Loss and Renewal in the Search for Identity. London, UK: Routledge, 1998.

36 Moulder C. Understanding Pregnancy Loss. Perspectives and Issues in Care. London, UK: Macmillan, 1998.

37 Rando T. Parental Loss of a Child. Champaign, IL: Research Press, 1986

38 Barger-Williams G. Induced elective abortion and perinatal grief. Dissertation thesis, New York University, New York, NY, USA, 1991. Available from UMI Dissertation Services, Ann Arbor, MI, USA (www.il.proquest.com).

39 Dyson L, While A. Termination of pregnancy: a difficult decision making process. Br J Community Nurs 1999; 4: 476-482.

40 Zapka J, Lemon S, Peterson L, Palmer H, Goldman M. The silent consumer. Med Care 2001; 39: 50-60.

\section{BOOK REVIEW}

We Need to Talk About Kevin (L Shriver). London, UK: Serpent's Tail, 2005. ISBN-13: 978-1-852-42889-1 Price: £7.99. Pages: 436 (paperback)

Early in this book you learn that Kevin is in prison after killing classmates at his school (a subject I would normally avoid). The book format is of the letters written by his mother, Eva, to her absent husband. The letters recount Eva's interpretations and emotions about Kevin's early and teenage years. The format limits the exploration of the themes in some ways, but also allows the reader to form an opinion about Eva, mostly unfavourable, as she obviously dislikes herself. Well written, the letters carry the reader compulsively through all the unpleasant events and later horrors.

Why is a book about the peculiar phenomenon of teenage killers of interest to health professionals? The letters have an appeal in a personal way to many women who have enjoyable pre-parenting lives that are, or would be, utterly changed by motherhood. Eva, the founder and chief executive of a travel book company, decides to have a baby mainly to please her husband, who feels he is not complete without. (Or perhaps, he resents her success and feels that having a baby will reduce her hubris?) The letters describe the loss of status and purpose, the lack of reward, and feelings of responsibility for everything the child does, as well as the change in circumstances that are so familiar to many mature women embarking on parenthood. It also illustrates many of the fears and fantasies that we hear in the consulting room from women thinking about embarking on pregnancy, or who are already pregnant. For example, the feeling that the body and later, the mother's life, is taken over by an alien being, sucking the life force out. Or the fear that the baby will be a monster, as indeed Kevin turns out to be. He is so difficult to look after and get along with, that au pairs, babysitters, and even coattendees at nursery school flee. In psychoanalytical terms, the loss of Eva's own childhood to her own agoraphobic mother might lead to identification of the child as a rival. Eva describes her coldness, boredom and exhaustion, far from the accepted picture of joy and absorption that mothers are 'supposed' to feel.

The conviction that she will deliver her baby without an epidural, the perceived unkindness of the birth attendants, the impossibility of bonding to the baby or of breastfeeding are familiar scenarios to any health professionals involved in women's care. Here they are wearily described in the uncompromising style of Eva's letters to her husband. Eva recounts how difficult Kevin is to care for, only for Franklin, the uncomprehending father, to increasingly believe that she is untruthful or even deranged. The dialogue between Eva and Kevin during Eva's visits to the prison gives a clear insight into Kevin's maturing. She recounts her experience of Kevin coming out of that temporary madness that is part of adolescence, and which must bear some of the responsibility for his bizarre actions.

Eva scrutinises her own behaviour and tries to determine how much responsibility she must bear for Kevin's anger and cruelty, subscribing to the myth that if things go wrong, "It must be the fault of the parents." How often do we hear mothers praised for being marvellous parents when their children do well? Oh, that's just "She was lucky to have such a gifted, pleasant, successful child". Eva's description of her second child - pleasant, passive and fearful - might contradict the premise that the responsibility is solely parental. Society blames her, she blames herself and punishes herself for what has happened, but the novel leaves the reader uncertain by how much she should be held to blame for this instance of violence - one of the many spectacles that fill our TV screens and strangely fascinate so many of us.

No, I didn't enjoy the book, but it was absorbing.

Reviewed by Gill Wakley, MD, FFSRH Advisory Editor, Journal of Family Planning and Reproductive Health Care

We hope that journal readers enjoyed reading We Need to Talk About Kevin, and also discovering whether their opinion of the book matched that of our guest reviewer. In the October issue, the fiction book under scrutiny will be Christine Falls by Benjamin Black (400 pages, Picador, 2007, ISBN-13: 978-0-33044-532-0). We want to remind journal readers that if they would like to offer to review an appropriate fiction title of their own choosing then they should contact the Journal Editorial Office by e-mail (journal@fsrh.org) in the first instance with details of their nominated title. 